\title{
Subcutaneous Implantable Cardioverter Defibrillator (S-ICD) Electrode Fracture: Follow-up, Troubleshooting and Evaluation
}

\author{
Danesh Kella ${ }^{1}$ and Bruce Stambler ${ }^{2}$ \\ ${ }^{1}$ Mayo Clinic \\ ${ }^{2}$ Piedmont Heart Institute
}

February 4, 2021

\begin{abstract}
Introduction: The subcutaneous-ICD (S-ICD) and its electrode were developed to avoid long-term complications of transvenous leads in the vasculature. Methods: We report a case of unexpected, inappropriate S-ICD shocks due to oversensing of high amplitude, non-physiologic, electrical noise artifacts that were not preceded by high impedance alerts or sensing electrogram noise detections. Results: Following explant, high-magnification, X-ray imaging of the S-ICD electrode demonstrated partial fracture of the distal sensing conductor located near a short radius bend in the electrode at the electrode-header interface. Conclusions: Clinicians should be aware of a potential for fatigue failure fracture of the S-ICD electrode. Recommendations for systematic S-ICD follow-up and troubleshooting are discussed.
\end{abstract}

\section{Hosted file}

Sub Q ICD Case report Final.pdf available at https://authorea.com/users/393627/articles/ 507216-subcutaneous-implantable-cardioverter-defibrillator-s-icd-electrode-fracturefollow-up-troubleshooting-and-evaluation 